\title{
The chaperone-usher pathway of bacterial adhesin biogenesis - from molecular mechanism to strategies of anti-bacterial prevention and modern vaccine design ${ }^{\star}$
}

\author{
Rafał Piątek, Beata Zalewska, Katarzyna Bury and Józef Kur ${ }^{\bowtie}$ \\ Department of Microbiology, Gdańsk University of Technology, Poland; ${ }^{\circledR}$-mail: kur@chem.pg.gda.pl
}

Received: 15 March, 2005; revised: 12 July, 2005; accepted: 28 July, 2005

available on-line: 15 September, 2005

\begin{abstract}
The chaperone-usher system determines the biogenesis of surface-exposed adhesive structures responsible for virulence of many Gram-negative bacteria. Investigations of the last 20 years have resolved the mechanism of this pathway on a structural level for different species of pathogenic bacteria. The purpose of this review is to present the molecular mechanisms of the biogenesis of adhesive structures assembled via the chaperone-usher pathway. The obtained mechanistic data allow one to propose potential strategies of anti-bacterial action. Additionally, the specific properties of the polymeric adhesive structures (pili and fimbriae) of the chaperone-usher system allow their use as effective and safe recombinant vaccines carrying foreign epitopes in thousands of copies on bacterial cell surface.
\end{abstract}

Keywords: adhesion, pili, fimbriae, chaperone-usher pathway

\section{OUTLINE OF VIRULENCE FACTORS}

Pathogenic bacteria and natural bacterial flora of the host organism possess surface adhesive structures which enable the colonization of specific target tissues. The presence of specific adhesion factors on the bacterial cell surface also determines the tropism of the pathogen to the tissues expressing specific receptors. Adhesive factors of pathogenic bacteria are highly differentiated structures with regard to tissue tropism (receptor specificity) and assisted mechanisms allowing for the survival of bacterial cells under the conditions of mechanic stress and the functioning of the host's immune system (Finlay \& Falkow, 1997; Mulvey, 2002). Bacterial adhesins are able to recognize carbohydrate receptors (e.g., PapG and FimH) as well as peptide elements (e.g., Dr family of adhesins) (Lund et al., 1987; Krogfelt et al., 1990; Van Loy et al., 2002a; 2002b). A single adhesive system may be able to recognize a few receptors, for example a specific receptor determining tissue tropism and structural elements of the basement membrane (e.g., collagen). The binding ability of bacteria to the elements of basement membrane predisposes them to cause recurrent and chronic infections. Bacterial gene clusters often con- tain additional genes encoding invasion factors. Invasins usually recognize a specific kind of receptors (other than adhesive factors) and are responsible for the effective internalization of bacteria into the host cells.

Adhesive organelles of Gram-negative bacteria assembled with the common chaperone-usher mechanism are the best characterized ones. On a structural level, the chaperone-usher mechanism is best known for the uropathogenic Escherichia coli strains encoding type 1 and P pili, Dr family of adhesins and polymeric F1 capsular antigen of Yersinia pestis (reviewed in: Zavialov et al., 2003; Anderson et al., 2004; Sauer et al., 2004; Pettigrew et al., 2004).

\section{STRUCTURE OF ADHESIVE ORGANELLES ASSEMBLED WITH THE CHAPERONE-USHER SYSTEM}

Bacterial cells and host tissue cell surfaces possess a negative net charge which repulses adhesion. Therefore, bacteria have developed adhesive organelles which are protein polymers with a tip adhesive factor located distally to the bacterial surface (Donnenberg, 2000). 
The adhesive structures assembled with the chaperone-usher system are homopolymers composed of a single protein subunit (e.g., Dr fimbriae, F1 antigen) or heteropolymers composed of a few different protein subunits at various stoichiometries (e.g., type 1 pili and P pili) (reviewed in: Zavialov et al., 2003; Anderson et al., 2004; Sauer et al., 2004; Pettigrew et al., 2004). The heteropolymeric organelles have a distinct structure of two fragments: a rigid fimbrial filament and a thin tip-fibrillum with the adhesin subunit at the filament tip. The P pili encoded by the pap operon of uropathogenic E. coli consist of a rigid rod, 5-7 $\mu \mathrm{m}$ in length, and a diameter of $6.8 \mathrm{~nm}$ (Kuehn et al., 1992). This rod is a polymer of the PapA major subunit forming a right-handed helix with a pitch of $2.5 \mathrm{~nm}$ and 3.3 subunits per turn (Gong \& Makowski, 1992; Bullitt \& Makowski, 1995). The fibrillum located at the tip of $\mathrm{P}$ pili is $30 \mathrm{~nm}$ in length and is a polymer of the PapE protein. The PapG adhesin located at the tip of $P$ pili is connected with the fibrillum by the PapF adaptor subunit. The fibrillum in turn is connected with the rigid rod by the PapK adaptor subunit (Gong \& Makowski, 1992; Jacob-Dubuisson et al., 1993). Type 1 pili encoded by the fim operon of uropathogenic E. coli have a very similar structure. The rod of type 1 pili is composed of FimA subunits which are connected (by the FimF protein subunit) with a thin fibrillum consisting of FimG subunit and a tip adhesin subunit FimH (Jones et al., 1995; Hahn et al., 2002; Saulino et al., 2000). The PapG adhesin is specific for digalactosides (Lund et al., 1987); the minor proteins of $\mathrm{P}$ pili, PapE and PapF, mediate adhesion to fibronectin (Westerlund et al., 1991). The FimH adhesin is mannose-specific. Some variants of this protein recognize fibronectin and collagen (Krogflet et al., 1990; Sokurenko et al., 1994; Pouttu et al., 1999).

Homopolymeric adhesive organelles are less structured than the heteropolymeric ones. They have the form of thin fimbriae resembling the fibrillum of $\mathrm{P}$ and type 1 pili (e.g., Dr fimbriae encoded by the dra operon of uropathogenic E. coli strains; Nowicki et al., 1989) or of afimbrial capsules surrounding the bacterial cell (e.g., capsules of Afa-III encoded by the afa-III operon of uropathogenic E. coli strains or nonfimbrial F1 capsular antigen encoded by the caf operon of Y. pestis; Nowicki et al., 1990; Miller et al., 1998). Dr fimbriae are homopolymers composed of DraE subunits which are also an adhesin recognizing the Dr ${ }^{\mathrm{a}}$ blood-group antigen on decay-accelerating factor DAF (Van Loy et al., 2002a; 2002b) and the $7 \mathrm{~S}$ fragment of type IV collagen (Westerlund et al., 1989; Selvarangan et al., 2004).

The consecutive subunits of heteropolymeric and homopolymeric adhesive structures are connected by non-covalent interactions in a head-totail arrangement. The different morphology (level of rigidity) of various types of adhesive systems is determined mainly by higher order interactions of the consecutive subunits of the polymer. The aminoacid sequence of the DraE adhesive subunit contains three amino-acid residues different from the homologous AfaE-III protein but the crystallographic structures of the above proteins are almost identical (Anderson et al., 2004; Pettigrew et al., 2004). However, the interactions between the DraE or AfaE-III subunits lead to the creation of different polymeric structures. DraE subunits form thin hair-like fimbriae and AfaE-III subunits form afimbrial structures. Additional interactions between subunits also increase the resistance of the polymer to chemical and physical factors and to degradation by proteases (shown for different polymeric structures; Zavialov et al., 2002; Piątek et al., 2005).

\section{CHAPERONE-USHER MECHANISM OF BIOGENESIS}

The surface-located adhesive structures enable the survival of bacterial cells under specific conditions. For that reason the chaperone-usher mechanism of biogenesis is highly conserved among Gram-negative bacteria. The genetic organization of the gene clusters encoding the polymeric systems of the chaperone-usher type is very similar. Each operon encodes three types of functional proteins: proteins regulating the transcription and translation of the gene cluster, protein or proteins which are the structural subunits of the polymers, and proteins essential in the biogenesis of the polymeric structures - an usher and a chaperone. For the first time the chaperone-usher mechanism (at a structural level) was determined for type 1 pili and P pili (Holmgren \& Branden, 1989; Choudhury et al., 1999; Sauer et al., 1999; 2002), followed by nonfimbrial, fimbrial and amorphic structures (e.g., F1 capsular antigen of Y. pestis, Dr fimbriae and Afa-III afimbrial shaft of uroptahogenic E. coli strains) (Zavialov et al., 2003; Anderson et al., 2004; Pettigrew et al., 2004).

The protein subunits of polymers are synthesized in the cytoplasm and secreted into the periplasm by means of the type II secretory system. The subunits expressed in the absence of the chaperone aggregate, form inclusion bodies or are degraded by cellular proteases (Jones et al., 1997; Zavialov et al., 2002; Piątek et al., 2005). The subunits are not able to fold spontaneously to form structures that are capable of polymerization. The crystallographic structures of type 1 and $\mathrm{P}$ pili subunits show that they have an immunoglobulin-like (Ig-like) structure (Fig. 2B) (Choudhury et al., 1999; Sauer et al., 1999). A classical Ig structure is composed of seven antiparallel $\beta$-strands ( $\beta$ A to $\beta G$ ) forming a flattened barrel composed of two $\beta$-sheets. The Ig-like structure of pili subunits is incomplete with the seventh $G \beta$ - 
strand missing (Fig. 2B). This causes the formation of a hydrophobic groove in the structure of the subunit flanked by the A and $\mathrm{F} \beta$-strands. The subunits without the seventh $\beta$-strand are not able to form spontaneously a stable Ig-like structure (reviewed in Sauer et al., 2004).

A fundamental protein in the biogenesis of polymeric adhesive structures is the chaperone. A subunit forms a soluble complex with the chaperone directly after translocation into the periplasm. On the basis of the steric information of the chaperone structure, the subunits fold to a native form capable of polymerization. Formation of stable complexes with the chaperone protects the subunits from aggregation, degradation by proteases and spontaneous polymerization. The chaperone-subunit complexes are able to polymerize in contact with an usher protein (an outer-membrane channel) to form surface-located adhesive polymers (reviewed in Sauer et al., 2004).

The chaperones possess a conserved structure which is connected with their crucial function in the biogenesis process (Fig. 1). They are composed of two Ig-like domains forming a boomerang-like structure (Holmgren \& Branden, 1989; Choudhury et al., 1999; Sauer et al., 1999; Knight et al., 2002). The N-terminal domain contains a functionally important G1 $\beta$-donor strand which, in the chaperone-subunit complex, completes the Ig-like structure of the subunit by a donor strand complementation mechanism. The G1 donor $\beta$-strand contains alternating hydrophobic residues which complement the core of the subunit by interactions with the hydrophobic residues of the F $\beta$-strand (Fig. 1C) (Hung et al., 1999). The second fundamental element in the structure of the chaperone (essential in the formation of the complex with the subunit) is two highly conserved residues - homologs of Arg8 and Lys112 of the PapD chaperone (Fig. 1A and 1C) (Slonim et al., 1992; Kuehn et al., 1993). The residues are located in a cleft between two functional domains of the chaperone. They are responsible for the anchorage of the C-terminal carboxylate at the end of the $\mathrm{F}$ $\beta$-strand of the subunit. This interaction guarantees proper orientation between the G1 donor $\beta$-strand of the chaperone and the $\mathrm{F} \beta$-strand of the subunit.

Sequence- and structural analysis justifies the division of the chaperones into two groups. The basis of this division is the number of residues in the loop connecting the G1 donor $\beta$-strand with the F1 $\beta$-strand of the N-terminal domain. Chaperones with a long F1-G1 loop (FGL chaperones, e.g., Caf1M of $Y$. pestis caf operon and DraB of E. coli dra operon) are connected with the biogenesis of homopolymeric structures. Chaperones with a short F1-G1 loop (FGS chaperones, e.g., PapD of E. coli pap operon and FimC of E. coli fim operon) are essential in the biogenesis of heteropolymeric structures (Hung et al., 1996). The characteristic feature of the FGL subfamily of chaperones is the presence of two conserved cysteine residues forming a disulfide bond. Site-directed mutagenesis of the Caf1M and DraB chaperones showed that this disulfide bond is indispensable for the formation of the subunit-chaperone complex (Zav'yalov et al., 1997; Piątek et al., 2005).

Every fiber subunit possesses an N-terminal donor extension which, like the G1 $\beta$-strand of the chaperone, contains alternating hydrophobic residues. Crystal data show that this N-terminal extension does not contribute to the subunit Ig-like fold and is not visible in the structure (Sauer et al., 1999). A deletion of the first three amino-acid residues of the DraE protein blocked the polymerization process without interfering with the formation of complexes with the DraB chaperone (Piątek et al., 2005). Crystallographic data of a complex of the Caf1M chaperone with two Caf1 subunits (Zavialov et al., 2003), and biogenesis data of $\mathrm{P}$ and type 1 pili show that during the course of polymerization, the N-terminal donor extension of the incoming subunit depletes the G1 donor $\beta$-strand of the chaperone, completing the Ig-like fold of the last subunit of the growing polymer (reviewed in Sauer et al., 2004). The described process is called a donor strand exchange mechanism. In this manner, during the biogenesis of the polymeric organelles by the chaperone-usher mechanism, the Ig-like structure of one subunit is always stabilized by the donor strand of another subunit.

The polymerization process on the basis of the outer-membrane channel (formed by the usher) is performed without ATP consumption or electrochemical gradients (Jacob-Dubuisson et al., 1994). The crystallographic structure of the Caf1M chaperone with two Caf1 subunits (Zavialov et al., 2003) and a comparison of the structure of the PapE subunit-PapD chaperone complex with that of PapE bound to a peptide corresponding to the N-terminal donor extension of PapK subunit (Sauer et al., 2002) explains the energetic aspects of the polymerization process. In the chaperone-subunit complex, the donor G1 $\beta$-strand of the chaperone is parallel to the $\mathrm{F} \beta$-strand of the subunit forming an Ig-like fold. However, in the classical Ig fold, the seventh G $\beta$ strand is antiparallel to the F $\beta$-strand. The crystal data show that the subunit bound to chaperone has a core with a poorly optimized interaction system. This is connected with the specific interaction of the donor G1 $\beta$-strand with amino-acid residues forming the acceptor cleft. Therefore the folding energy is stored in a molten globule-like conformation of the subunit during the formation of the chaperonesubunit complex. In a donor strand exchange reaction, the $\mathrm{N}$-terminal donor extension of one subunit is placed antiparallel to the $\mathrm{F} \beta$-strand of the second subunit - this results in the formation of a canonical Ig fold. The core of the subunit in a polymer struc- 

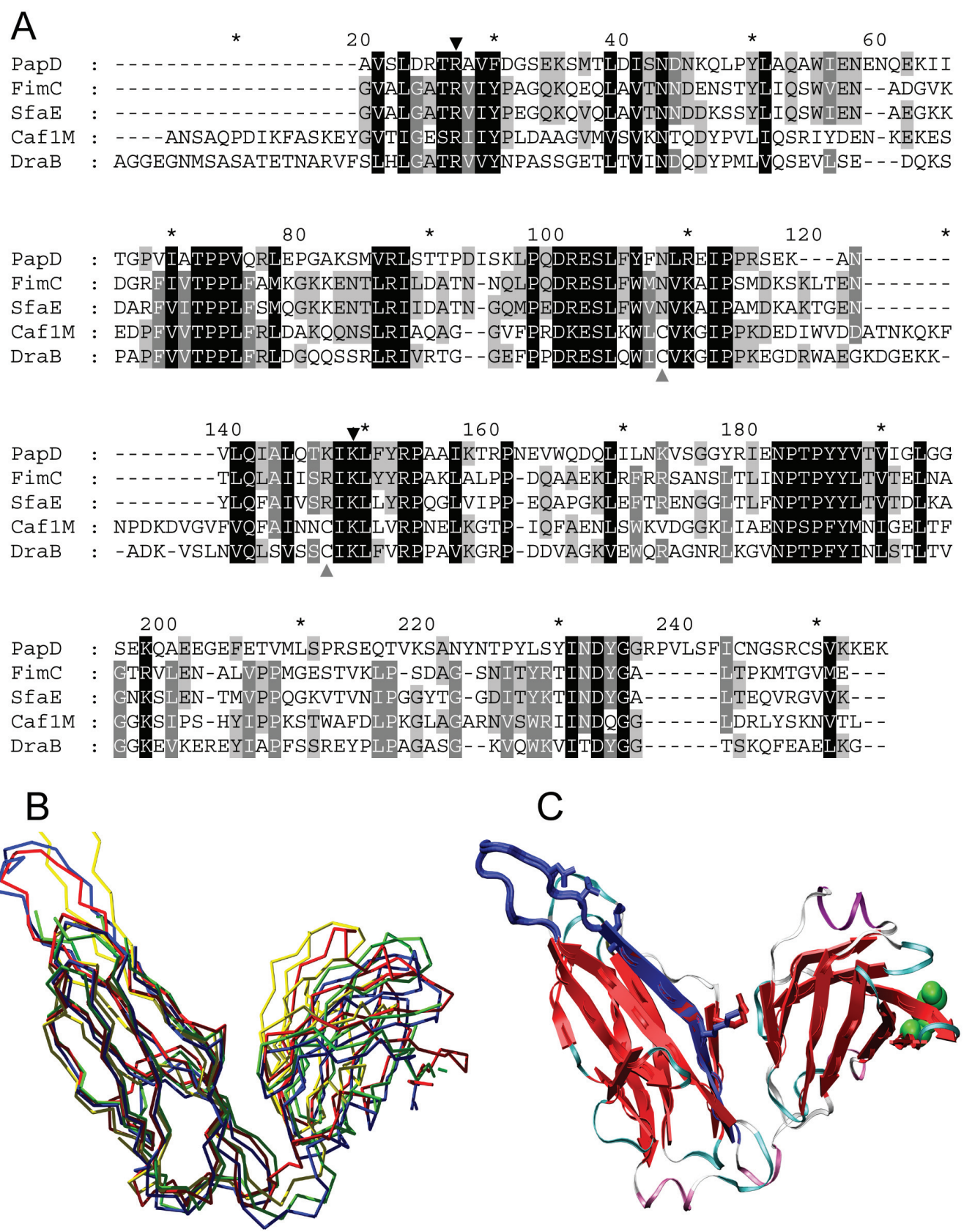

Figure 1. A. Alignment of the amino-acid sequences belonging to FGS (PapD, FimC, SfaE) and FGL (Caf1M, DraB) subfamilies of periplasmic chaperones.

The level of similarity is indicated as follows: white type with black background, $100 \%$ similarity; white type with gray background, $>80 \%$ similarity and black type with gray background, $>60 \%$ similarity. The black triangles indicate Arg and Lys residues (homologs of Arg8 and Lys112 of PapD) invariant in the whole family. The gray triangles denote conserved cysteines that form disulfide bonds characteristic only for FGL subfamily. The region of analysis between 120 and 140 corresponds to loops connecting $\beta$-strands F1 and G1.

B. Alignment of structures of the following chaperones: PapD (red), FimC (blue), SfaE (green) and Caf1M (yellow). The structures are represented as $\mathrm{C} \alpha$ traces. A characteristic feature is the high structural fit of the N-terminal domains (on left in figure) in relation to the C-terminal domains (on right in figure) of analyzed structures.

C. Ribbon view of PapD protein indicating characteristic boomerang-like arrangement of the N- and C-terminal domains (left and right in figure, respectively).

In the diagram the conserved elements in donor strand complementation reaction are denoted. Blue strand represents donor $\beta$-strand G1 which is connected with $\beta$-strand F1 by FG-loop (denoted in blue). In the region corresponding to donor strand the three alternating hydrophobic residues Leu103, Ile105 and Leu107 (interacting with residues from hydrophobic grove of subunit) are indicated by stick model. In the interface between N- and C-terminal domains of PapD the conserved Arg8 (red stick model) and Lys112 residues (blue stick model) engaged in anchorage of subunit are located. The C-terminal residue of PapD is presented in green by a space-fill model. GenBank accession numbers: PapD, gi:96248; FimC, gi:729490; SfaE, gi:14594876; Caf1M, gi:17380416; DraB, gi:40388417. Protein Databank accession codes: 1PDK (complex PapD-PapK), 1KLF (FimC-FimH), 1L4I (SfaE) and 1P5V (Caf1M-Caf1). 
ture is well packed with optimized interactions. This structural analysis suggests that the folding energy of the collapse of the subunit core (during the donor strand exchange reaction) drives the polymerization (Sauer et al., 2002; Zavialov et al., 2003).

\section{ANTIBACTERIAL STRATEGIES BASED ON THE MECHANISM OF THE CHAPERONE-USHER SYSTEM}

The adhesive polymeric structures assembled with the common chaperone-usher mechanism are unique to Gram-negative bacteria. They are crucial in the attachment to host tissues, colonization and recurrent or chronic infections. For that reason they are an attractive target for the design of antibacterial agents. On the basis of the well characterized molecular mechanism of bioassembly of the adhesive polymeric structures, potential anti-bacterial strategies based on three different points of this process can be proposed: (i) inhibition of the chaperone-subunit complex formation, (ii) halting the polymerization process at the level of chaperone-subunit complex interactions with an usher protein, and (iii) inhibition of bacterial attachment to the receptor localized on the surface of host cells by anti-adhesin antibodies. The chaperones are a highly conserved group of proteins with a crucial role in the biogenesis of adhesive structures. A pair of Lys and Arg residues (the anchorage of the C-terminal end of the subunit) is the most conserved element among the FGL and FGS groups of chaperones (Fig. 1A and 1C). On the basis of the above property and the crystal data of PapD and FimC chaperones with cognate subunits and peptides, a group of antibacterial agents called "pilicides" (derivatives of amino acids and pyridinones) was designed (Svensson et al., 2001). The above compounds block the formation of chaperone-subunit complexes by reason of specific and strong binding to chaperones in the place of the interaction with the subunit. The obtained compounds bound specifically with the PapD as well as FimC chaperones. Some pilicides were able to dissociate the chaperone-subunit complexes, which guarantees effective inhibition of the formation of adhesive structures.

The mechanism of polymerization based on the interaction of a chaperone-subunit complex with an usher protein is relatively poorly characterized (Barnhart et al., 2003; Ng et al., 2004; Henderson et al., 2004; Li et al., 2004). This process can also be a quite good target for the design of anti-bacterial agents on account of their crucial role in the bioassembly process. However, until now no data have been published about potential pilicides interfering with the polymerization process, based on the usher protein.
E. coli strains are the main causative agents of urinary tract infections (UTI) in humans: $85 \%$ of acute cystitis and pyelonephritis, $60 \%$ of recurrent cystitis and $35 \%$ of recurrent pyelonephritis (Barnett \& Stephens, 1997). The E. coli strains expressing type 1 pili are the cause of cystitis connected with binding of FimH adhesin to mannose receptors along the bladder mucosa (Langermann et al., 1997). Langermann and coworkers (2000) tested complexes of the FimH adhesin and FimC chaperone (FimCH) in various animal models (murine and monkey cystitis models) as a potential vaccine against E. coli UTI. Active immunization of mice with FimCH reduced colonization of the bladder mucosa by uropathogenic E. coli by over $99 \%$ in the murine cystitis model. The efficacy of the FimCH vaccine was also confirmed by monkey immunization (Langermann et al., 2000). The performed experiments showed that the $\mathrm{FimCH}$ vaccine developed a high level of serum IgG which after transduction into urogenitalia blocked mucosal infections by uropathogenic E. coli.

The presented data suggest that antibodies specific to adhesin molecules can block infections that are dependent on a specific interaction between host receptors and bacterial adhesins. In the case of heteropolymeric pili with a tip adhesin the immunization of animals with chaperone-adhesin complexes is efficacious. However, in the case of homopolymeric structures consisting of a single subunit with adhesive function (e.g., Dr fimbriae composed of DraE adhesin) there is a possibility to use chaperone-subunit complexes and purified fimbriae for immunization (Goluszko et al., 2005). The studies concentrating on the molecular mechanism of biogenesis of polymeric structures (via the chaperoneusher system) elaborated very efficient methods of isolation and purification of the chaperone-adhesin complexes and also fimbrial fractions.

\section{RECOMBINANT FIBERS AS UNIVERSAL CARRIERS OF ANTIGENIC EPITOPES}

Type 1 pili are found in as many as 500 copies per cell. The core of the pili is a polymer composed of 1000 FimA subunits. The polymerization process via the chaperone-usher mechanism is highly conserved among Gram-negative bacteria. The polymeric subunits display low level of sequence homology but possess conserved Ig-like structure (Fig. 1B and 2B). The DraE subunit of Dr fimbriae (dra operon) differs in three amino-acid residues from afimbrial AfaE-III adhesin (afa-III operon). The three differences between DraE and AfaE-III result in different morphology of both adhesins, but do not influence the chaperone-subunit complex formation and polymerization reaction. The chaperone and usher proteins encoded by the $d r a$ and afa-III gene clusters 
A

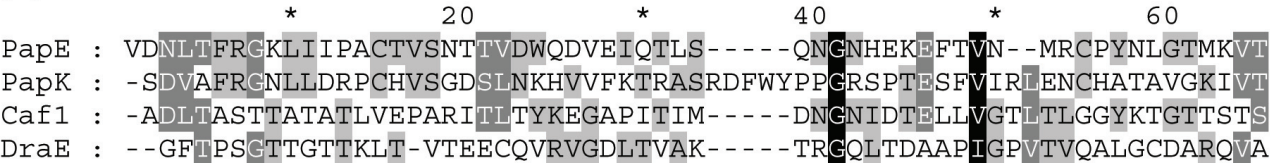

PapE : ITATNTYNNAILVQNTS-NTSSDGLLVYLYNSNAGNIGTAITLGTPFTPGKITGNNADKTISLHA PapK : LTFKGTEEAALPGHLKVTGVNAGRLGIALLDTDGSSLLKPGTSHNKGQGEKVTGNSLELPFGAYV Caf1 : VNFTDAAGDPMYLTFTSQDGNNHQFTTKVIGKDSRDFDISPKVNGENLVGDDV-VLATGSQDFF DraE : LKADTDNFEQGKFFLIS-DNNRDKLYVNIRPTDNSAWTTDNGVFYKNDVGS- - -WG- - GIIGIYV

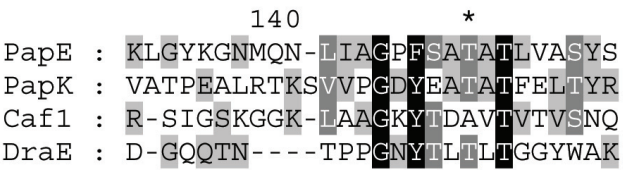

B

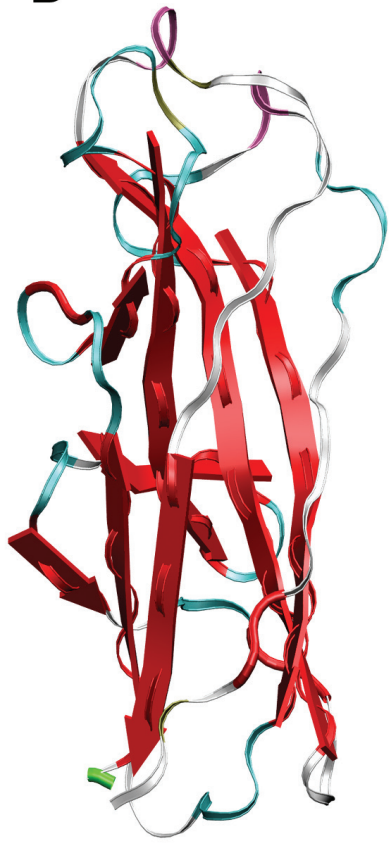

PapE

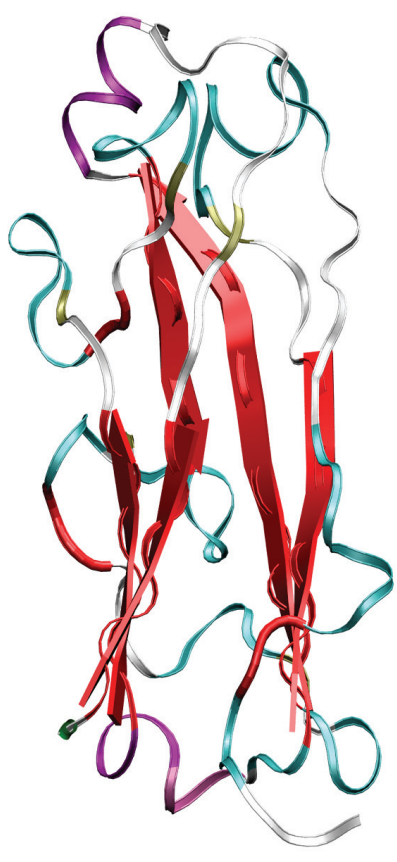

PapK

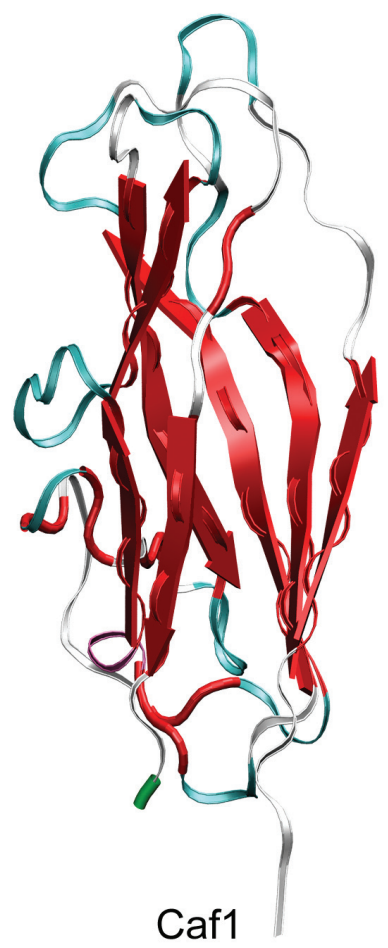

Caf1

Figure 2. A. Alignment of the amino-acid sequences of subunit proteins of hetreropolymeric:

PapE (structural element of fibrillum of P pili), PapK (adapter subunit of P pili) and homopolymeric: Caf1 (F1 capsular antigen) adhesive structures. The level of identity and similarity as in the legend to Fig. 1.

B. Ribbon diagram of structures of PapE, PapK and Caf1 proteins.

The structures are orientated to show the absence of the seventh $\beta$-strand $\mathrm{G}$ in the Ig-like folds of subunits. The C-terminal residue of subunits corresponding to location of $\beta$-strand $\mathrm{F}$ is denoted in green. GenBank accession numbers: PapE, gi:72817; PapK, gi:96256; Caf1, gi:48621; DraE, gi:13241936. Protein Databank accession codes: 1PDK (complex PapDPapK), 1N12 (PapE with bound N-terminal extension of PapK) and 1P5V (Caf1M-Caf1).

exhibit 100\% identity (Anderson et al., 2004). It has been demonstrated that the chaperone-usher biogenesis system of adhesive structures is rather little sensitive to naturally occurring or artificial changes in subunit sequence. Therefore pili and fimbriae can be used as excellent carriers of foreign epitopes, which will be exposed in a thousand copies on the bacterial cell surface. Pili and fimbriae are very good immunogens (Moon \& Bunn, 1993; Levine et al., 1994), and the procedure of purification of fimbrial fraction is very simple (Hedegaard \& Klemm, 1989; Zalewska et al., 2003). Thus, chimeric pili/fimbriae with inserted antigenic sequences can be used as effective and safe recombinant vaccines. The main problem in the construction of chimerical pili/fimbriae is the localization of the insertion region, especially in the absence of structural data of fimbrial subunits. The insertion position chosen must not interfere with the 
chaperone-subunit complex formation and polymerization. For the proteins which are the major building element of the polymer, the size of the inserted peptide should be in the 10-30 amino-acid range (reviewed in: Stentebjerg-Olsen et al., 1997; Klemm \& Schembri, 2000a; 2000b). The range was determined for heteropolymeric pili characterized by the wide network of interactions between the subunits of the polymer. In the case of homopolymeric fimbriae which are thick, flexible hair-like filaments the size of the epitope can be even larger. The inserted peptide should be relatively hydrophilic and devoid of cysteine residues. The presence of cysteines in passenger sequences is not accepted by fimbrial subunits which contain these residues forming a disulfide bond (e.g., DraE of Dr fimbriae) (Zalewska et al., 2003; Piątek et al., 2005). Studies performed on animal models confirm the immunogenicity of various epitope sequences inserted in different types of chimeric pili/fimbriae (e.g., heteropolymeric type 1 pili, P pili, 987P pili, K88 pili and homopolymeric Dr fimbriae) (reviewed in Klemm \& Schembri, 2000a; 2000b).

\section{Acknowledgements}

This work was supported by the State Committee for Scientific Research (projects No. 3 P05A 07923 and 2 P04A 03927 to J.K).

\section{REFERENCES}

Anderson KL, Billington J, Pettigrew D, Cota E, Simpson $\mathrm{P}$, Roversi P, Chen HA, Urvil P, du Merle L, Barlow PN, Medof ME, Smith RA, Nowicki B, Le Bouguenec C, Lea SM, Matthews S (2004) An atomic resolution model for assembly, architecture, and function of the Dr adhesins. Mol Cell 15: 647-657.

Barnhart MM, Sauer FG, Pinkner JS, Hultgren SJ (2003) Chaperone-subunit-usher interactions required for donor strand exchange during bacterial pilus assembly. I Bacteriol 185: 2723-2730.

Barnett BJ, Stephens DS (1997) Urinary tract infection: an overview. Am J Med Sci 314: 245-249.

Bullitt E, Makowski L (1995) Structural polymorphism of bacterial adhesion pili. Nature 373: 164-167.

Choudhury D, Thompson A, Stojanoff V, Langermann S, Pinkner J, Hultgren SJ, Knight SD (1999) X-ray structure of the FimC-FimH chaperone-adhesin complex from uropathogenic Escherichia coli. Science 285: 1061 1066.

Donnenberg MS (2000) Pathogenic strategies of enteric bacteria. Nature 406: 768-774.

El Mazouari K, Oswald E, Hernalsteens JP, Lintermans P, De Greve H (1994) F17-like fimbriae from an invasive Escherichia coli strain producing cytotoxic necrotizing factor type 2 toxin. Infect Immun 62: 2633-2638.

Finlay BB, Falkow S (1997) Common themes in microbial pathogenicity revisited. Microbiol Mol Biol Rev 61: 136169.

Goluszko P, Goluszko E, Nowicki B, Nowicki S, Popov V, Wang HQ (2005) Vaccination with purified Dr fimbriae reduces mortality associated with chronic urinary tract infection due to Escherichia coli bearing Dr adhesin. Infect Immun 73: 627-631.

Gong M, Makowski L (1992) Helical structure of P pili from Escherichia coli. Evidence from X-ray fiber diffraction and scanning transmission electron microscopy. $J$ Mol Biol 228: 735-742.

Hahn E, Wild P, Hermanns U, Sebbel P, Glockshuber R, Haner M, Taschner N, Burkhard P, Aebi U, Muller SA (2002) Exploring the 3D molecular architecture of Escherichia coli type 1 pili. J Mol Biol 323: 845-857.

Henderson NS, So SS, Martin C, Kulkarni R, Thanassi DG (2004) Topology of the outer membrane usher PapC determined by site-directed fluorescence labeling. J Biol Chem 279: 53747-53754.

Hedegaard L, Klemm P (1989) Type 1 fimbriae of Escherichia coli as carriers of heterologous antigenic sequences. Gene 85: 115-124.

Holmgren A, Branden CI (1989) Crystal structure of chaperone protein PapD reveals an immunoglobulin fold. Nature 342: 248-251.

Hung DL, Knight SD, Woods RM, Pinkner JS, Hultgren SJ (1996) Molecular basis of two subfamilies of immunoglobulin-like chaperones. EMBO J 15: 3792-3805.

Hung DL, Knight SD, Hultgren SJ (1999) Probing conserved surfaces on PapD. Mol Microbiol 31: 773-783.

Jacob-Dubuisson F, Heuser J, Dodson K, Normark S, Hultgren SJ (1993) Initiation of assembly and association of the structural elements of a bacterial pilus depend on two specialized tip proteins. $E M B O J$ 12: 837-847.

Jacob-Dubuisson F, Striker R, Hultgren SJ (1994) Chaperone-assisted self-assembly of pili independent of cellular energy. J Biol Chem 269: 12447-12455.

Jones $\mathrm{CH}$, Pinkner JS, Roth $\mathrm{R}$, Heuser J, Nicholes AV, Abraham SN, Hultgren SJ (1995) FimH adhesin of type 1 pili is assembled into a fibrillar tip structure in the Enterobacteriaceae. Proc Natl Acad Sci USA 92: 20812085.

Jones CH, Danese PN, Pinkner JS, Silhavy TJ, Hultgren SJ (1997) The chaperone-assisted membrane release and folding pathway is sensed by two signal transduction systems. EMBO J 16: 6394-6406.

Knight SD, Choudhury D, Hultgren S, Pinkner J, Stojanoff V, Thompson A (2002) Structure of the S pilus periplasmic chaperone SfaE at $2.2 \AA$ resolution. Acta Crystallog, D Biol Crystallogr 58: 1016-1022.

Klemm P, Schembri MA (2000a) Fimbrial surface display systems in bacteria: from vaccines to random libraries. Microbiol 146: 3025-3032.

Klemm P, Schembri MA (2000b) Fimbriae-assisted bacterial surface display of heterologous peptides. Int J Med Microbiol 290: 215-221.

Krogfelt KA, Bergmans H, Klemm P (1990) Direct evidence that FimH protein is the mannose-specific adhesin of Escherichia coli type 1 fimbriae. Infect Immun 58: 1995-1998.

Kuehn MJ, Heuser J, Normark S, Hultgren SJ (1992) P pili in uropathogenic E. coli are composite fibers with distinct fibrillar adhesive tips. Nature 356: 252-255.

Kuehn MJ, Ogg DJ, Kihlberg J, Slonim LN, Flemmer K, Bergfors T, Hultgren SJ (1993) Structural basis of pilus subunit recognition by the PapD chaperone. Science 262: 1234-1241.

Li H, Qian L, Chen Z, Thibault D, Liu G, Liu T, Thanassi DG (2004) The outer membrane usher forms a twinpore secretion complex. J Mol Biol 344: 1397-1407.

Langermann S, Palaszynski S, Barnhart M, Auguste G, Pinkner JS, Burlein J, Barren P, Koenig S, Leath S, Jones CH, Hultgren SJ (1997) Prevention of mucosal 
Escherichia coli infection by FimH-adhesinbased systemic vaccination. Science 276: 607-611.

Langermann S, Mollby R, Burlein JE, Palaszynski SR, Auguste CG, DeFusco A, Strouse R, Schenerman MA, Hultgren SJ, Pinkner JS, Winberg J, Guldevall L, Soderhall M, Ishikawa K, Normark S, Koenig S (2000) Vaccination with FimH adhesin protects cynomolgus monkeys from colonization and infection by uropathogenic Escherichia coli. I Infect Dis 181: 774-778.

Levine MM, Giron J, Noriega F (1994) Fimbrial vaccines. In Fimbriae, Adhesion, Genetics, Biogenesis and Vaccine. Klemm P, ed, pp 271-286. Boca Raton, FL:CRC Press.

Lund B, Lindberg F, Marklund BI, Normark S (1987) The PapG protein is the $\beta$-D-galactopyranosyl-(1-4)- $\beta$-D-galactopyranose-binding adhesin of uropathogenic Escherichia coli. Proc Natl Acad Sci USA 84: 5898-5902.

Miller J, Williamson ED, Lakey JH, Pearce MJ, Jones SM, Titball RW (1998) Macromolecular organisation of recombinant Yersinia pestis F1 antigen and the effect of structure on immunogenicity. FEMS Immunol Med Microbiol 21: 213-221.

Moon HW, Bunn TO (1993) Vaccines for preventing enterotoxigenic Escherichia coli infections in farm animals. Vaccine 11: 213-220.

Mulvey MA (2002) Adhesion and entry of uropathogenic Escherichia coli. Cell Microbiol 4: 257-271.

Ng TW, Akman L, Osisami M, Thanassi DG (2004) The usher $\mathrm{N}$ terminus is the initial targeting site for chaperone-subunit complexes and participates in subsequent pilus biogenesis events. I Bacteriol 186: 5321-5331.

Nowicki B, Svanborg-Edén C, Hull R, Hull S (1989) Molecular analysis and epidemiology of the Dr hemagglutinin of uropathogenic Escherichia coli. Infect Immun 57: 446-451.

Nowicki B, Labigne A, Moseley S, Hull R, Hull S, Moulds J (1990) The Dr hemagglutinin, afimbrial adhesins AFA-I and AFA-III, and F1845 fimbriae of uropathogenic and diarrhea-associated Escherichia coli belong to a family of hemagglutinins with Dr receptor recognition. Infect Immun 58: 279-281.

Pettigrew D, Anderson KL, Billington J, Cota E, Simpson P, Urvil P, Rabuzin F, Roversi P, Nowicki B, du Merle L, Le Bouguenec C, Matthews S, Lea SM (2004) High resolution studies of the $\mathrm{Afa} / \mathrm{Dr}$ adhesin DraE and its interaction with chloramphenicol. J Biol Chem 279 46851-46857.

Piątek R, Zalewska B, Kolaj O, Ferens M, Nowicki B, Kur J (2005) Molecular aspects of biogenesis of Escherichia coli Dr Fimbriae: characterization of DraB-DraE complexes. Infect Immun 73: 135-145.

Pouttu R, Puustinen T, Virkola R, Hacker J, Klemm P, Korhonen TK (1999) Amino acid residue Ala-62 in the FimH fimbrial adhesin is critical for the adhesiveness of meningitis-associated Escherichia coli to collagens. Mol Microbiol 31: 1747-1757.

Saulino ET, Bullitt E, Hultgren SJ (2000) Snapshots of usher-mediated protein secretion and ordered pilus assembly. Proc Natl Acad Sci USA 97: 9240-9245.

Sauer FG, Fütterer K, Pinkner JS, Dodson KW, Hultgren SJ, Waksman G (1999) Structural basis of chaperone function and pilus biogenesis. Science 285: 1058-1061.

Sauer FG, Pinkner JS, Waksman G, Hultgren SJ (2002) Chaperone priming of pilus subunits facilitates a topological transition that drives fiber formation. Cell 111: 543-551.

Sauer FG, Remaut H, Hultgren SJ, Waksman G (2004) Fiber assembly by the chaperone-usher pathway. Biochim Biophys Acta 1694: 259-267.
Selvarangan R, Goluszko P, Singhal J, Carnoy C, Moseley S, Hudson B, Nowicki S, Nowicki B (2004) Interaction of Dr adhesin with collagen type IV is a critical step in Escherichia coli renal persistence. Infect Immun 72: 4827-4835.

Slonim LN, Pinkner JS, Branden CI, Hultgren SJ (1992) Interactive surface in the PapD chaperone cleft is conserved in pilus chaperone superfamily and essential in subunit recognition and assembly. EMBO J 11: 47474756.

Sokurenko EV, Courtney HS, Ohman DE, Klemm P, Hasty DL (1994) FimH family of type 1 fimbrial adhesins: functional heterogeneity due to minor sequence variations among fimH genes. J Bacteriol 176: 748-755.

Stentebjerg-Olesen B, Pallesen L, Jensen LB, Christiansen G, Klemm P (1997) Authentic display of a cholera toxin epitope by chimeric type 1 fimbriae: effects of insert position and host background. Microbiol 143: 2027-2038.

Svensson A, Larsson A, Emtenas $\mathrm{H}$, Hedenstrom M, Fex T, Hultgren SJ, Pinkner JS, Almqvist F, Kihlberg J (2001) Design and evaluation of pilicides: potential novel antibacterial agents directed against uropathogenic Escherichia coli. Chembiochem 2: 915-918.

Van Loy CP, Sokurenko EV, Samudrala R, Moseley SL (2002a) Identification of amino acids in the Dr adhesin required for binding to decay-accelerating factor. Mol Microbiol 45: 439-452.

Van Loy CP, Sokurenko EV, Moseley SL (2002b) The major structural subunits of Dr and F1845 fimbriae are adhesins. Infect Immun 70: 1694-1702.

Westerlund B, Kuusela P, Risteli J, Vartio T, Rauvala H, Virkola R, Korhonen TK (1989) The O75X adhesin of uropathogenic Escherichia coli is a type IV collagenbinding protein. Mol Microbiol 3: 329-337.

Westerlund B, van Die I, Kramer C, Kuusela P, Holthöfer H, Tarkkanen AM, Virkola R, Riegman N, Bergmans H, Hoekstra W, Korhonen TK (1991) Multifunctional nature of $\mathrm{P}$ fimbriae of uropathogenic Escherichia coli: mutations in $f_{S} O E$ and $f_{S} O F$ influence fimbrial binding to renal tubuli and immobilized fibronectin. Mol Microbiol 5: 2965-2975.

Zalewska B, Piątek R, Konopa G, Nowicki B, Nowicki S, Kur J (2003) Chimeric Dr fimbriae with a herpes simplex virus type 1 epitope as a model for a recombinant vaccine. Infect Immun 71: 5505-5513.

Zavialov AV, Kersley J, Korpela T, Zav'yalov VP, MacIntyre S, Knight SD (2002) Donor strand complementation mechanism in the biogenesis of non-pilus systems. Mol Microbiol 45: 983-995.

Zavialov AV, Berglund I, Pudney AF, Fooks LJ, Ibrahim TM, MacIntyre S, Knight SD (2003) Structure and biogenesis of the capsular F1 antigen from Yersinia pestis: preserved folding energy drives fiber formation. Cell 113: 587-596.

Zav'yalov VP, Chernovskaya TV, Chapman DA, Karlyshev AV, MacIntyre S, Zavialov AV, Vasiliev AM, Denesyuk AI, Zav'yalova GA, Dudich IV, Korpela T, Abramov VM (1997) Influence of the conserved disulphide bond, exposed to the putative binding pocket, on the structure and function of the immunoglobulin-like molecular chaperone Caf1M of Yersinia pestis. Biochem J 32: 571-578. 